\title{
Telomeres in Fishes
}

\author{
K. Ocalewicz \\ Department of Ichthyology, University of Warmia and Mazury in Olsztyn, Olsztyn, Poland
}

\section{Key Words}

Chromosomes · Chromosome fusions · Fish · Telomerase ·

Telomeres $\cdot$ Telomeric DNA sequences

\begin{abstract}
In fishes, as in other vertebrate species, the DNA component of the telomeres consists of the tandemly repeated TTAGGG motif. The length of the telomeric arrays in fishes ranges from 2 to $25 \mathrm{~kb}$ and shortens with age in some of the species. To date, chromosomal distribution of the telomeric DNA sequences has been examined in approximately 80 fish species of which about $42 \%$ show additional telomeric hybridization signals far from the chromosomal termini. Based on the chromosomal location, such internally located telomeric repeats may be classified into 4 categories: (1) telomeric DNA sequences located at the pericentromeric regions, (2) interstitial telomeric sites observed between centromeres and the bona fide telomeres, (3) telomeric DNA sequences that scatter along the nucleolus organizer regions, and (4) telomeric DNA repeats interspersed with the entire chromosomes. Most of the pericentromeric and interstitial telomeric sequences in fish are possible relicts of chromosome fusion events. The origin of the telomeric sequences colocalizing with the major rDNA sequences or scattered along the whole chromosomes is not clear. Internally located telomeric repeats are considered as 'hot spots' for recombination and thus may potentially increase the rates of chromosome breaks and rearrangements leading to the various
\end{abstract}

chromosomal polymorphisms in fishes. FISH with telomeric probe applied to metaphase spreads of androgenetic specimens that hatched from eggs exposed to ionizing radiation before insemination enabled the detection of small radiation-induced fragments of maternal chromosomes. Remnants of the irradiated chromosomes were found to be ring chromosomes with the interstitial telomeric signals, telomerless rings, fragments with fused sister chromatids, and linear fragments with telomeres detected at both of their ends. The increasing availability of techniques enabling the study of fish telomeres and telomerase and the easy access to numerous fish species strongly confirm that these animals are promising models in research concerning the role of telomeres and telomerase in vertebrate aging, repair of ionizing radiation-induced DNA double strand breaks, and chromosomal rearrangements.

(c) 2013 S. Karger AG, Basel

Telomeres are nucleoprotein complexes located at the ends of eukaryotic chromosomes. In all vertebrates studied to date, the DNA component of the telomeres contains a tandemly repeated G-rich hexanucleotide sequence (TTAGGG/CCCTAA) $n$ [Moyzis et al., 1988; Meyne et al., 1989]. The length of the telomeric DNA sequences varies significantly among species. Although an average size of the vertebrate telomeric repeats ranges from 10 to $20 \mathrm{~kb}$, much longer telomeric arrays extending from 30 to $150 \mathrm{~kb}$ or from $20 \mathrm{~kb}$ to approximately $4 \mathrm{Mb}$

\section{KARGER}

E-Mail karger@karger.com

www.karger.com/cgr (c) 2013 S. Karger AG, Base

$1424-8581 / 13 / 1413-0114 \$ 38.00 / 0$
Konrad Ocalewicz

Department of Ichthyology, University of Warmia and Mazury in Olsztyn Michala Oczapowskiego Street 5

PL-10719 Olsztyn (Poland)

E-Mail con@uwm.edu.pl 
are observed in some laboratory mice strains and chicken genetic lines, respectively [Kipling and Cooke, 1990; Delany et al., 2000; O’Hare and Delany, 2009]. Furthermore, variations in the length of the telomeric repeats have been observed between non-homologous and even homologous chromosomes within individuals [Landsorp et al., 1996; Londoño-Vallejo et al., 2001]. In the mouse, $p$ arm telomeres are shorter than their $q$ arm counterparts [Zijlmans et al., 1997].

Telomeres protect chromosomes from end-to-end fusions and degradation, guarantee their complete replication and allow DNA repair machinery to distinguish natural chromosomal ends from the ends that appear in the course of breakage events [de Lange, 2002; Bolzán and Bianchi, 2006]. Telomeric sequences may also be a component of the native satellite DNA [Garrido-Ramos et al., 1998]. Telomeres ensure proper chromosome topology in the nucleus and may silence genes located in the vicinity of the telomeric region [Ludérus et al., 1996; de Lange, 2002]. Telomeres shorten after each round of the cell division due to the 'end replication problem' [Olovnikov, 1973]. In several species, however, this loss may be compensated mainly by the telomerase, an enzyme whose catalytic protein subunit (telomerase reverse transcriptase) adds telomeric DNA repeats to the end of telomeres, using an integral RNA component as a template (telomerase RNA). Other cellular mechanisms, such as reciprocal recombination and transposition of the chromosomal terminal elements, may also be engaged in the telomere length maintenance [Biessmann and Mason, 1997].

Although telomeres, by definition, are terminal elements of the chromosomes, TTAGGG repeats are also observed at non-telomeric locations and are referred to as interstitial or internal telomeric sequences (ITSs), interstitial telomeric repeat sequences or interstitial telomeric bands. Based on the chromosomal location, length, DNA composition, and the origin, several kinds of the ITSs have been described [Bolzán and Bianchi, 2006; Lin and Yan, 2008; Ruiz-Herrera et al., 2008]. Internal telomeric sequences are usually considered as relicts of the ancient fusions of the ancestral chromosomes [Meyne et al., 1990]. Furthermore, telomeric DNA sequences may be inserted into the interstitial positions by the telomerase or transposition of the (TTAGGG) ${ }_{n}$ fragment to repair the DNA double strand breaks (DSBs) [Nergadze et al., 2007]. Although such ITSs are usually short (from a few tens to a few hundred base pairs), they are widely distributed in the genomes of several mammalian species [Nergadze et al., 2007; Ruiz-Herrera et al., 2008]. As ITSs sometimes co-localize with the breakage sites, interstitial telomeric arrays are considered as 'hot spots' for recombination [Ashley and Ward, 1993].

In recent years, many fish species have become promising vertebrate models in studies regarding the length of the telomeres and the expression of the telomerase during aging and tissue regeneration [Elmore et al., 2008; Anchelin et al., 2011]. Fluorescence in situ hybridization (FISH) with both conventional and peptide nucleic acid telomeric probes and primed in situ labeling with (TTAGGG) ${ }_{7} /$ $(\mathrm{CCCTAA})_{7}$ primers made the identification of telomeric DNA sequences in the chromosomes of approximately 80 fish species representing distant taxonomic groups possible [e.g. Fontana et al., 1998; Chew et al., 2002; Moreschalchi et al., 2002; Rocco et al., 2002]. In some of these species, telomeric DNA sequences located far from the chromosomal ends have been observed (table 1). Moreover, distribution of the telomeric DNA sequences on the $\gamma$ - and X-radiation-induced chromosome fragments was investigated in rainbow trout (Oncorhynchus mykiss) and brook trout (Salvelinus fontinalis) specimens provided by artificially induced androgenesis [Ocalewicz et al., 2004c, 2009a, 2012]. This paper reviews the current state of knowledge on the length and chromosomal localization of the telomeric DNA sequences in fishes. Special attention has been dedicated to the non-terminally located TTAGGG repeats. Mechanisms leading to the formation of the intrachromosomal telomeric sites, as well as their functions, are discussed here.

\section{Telomere Length in Fishes}

The length of the telomeric DNA arrays in fish shows interspecies variation and ranges from 2 to $25 \mathrm{~kb}$ [Lund et al., 2009; Downs et al., 2012]. Rather short telomeres are observed in some of the sharks and rays (about $3 \mathrm{~kb}$ ) [Rocco et al., 2001], in Nothobranchius furzeri (4.5-6.6 kb) [Hartman et al., 2009] and Xiphophorus fish species (2-6 kb) [Downs et al., 2012]. The Nile tilapia (Oreochromis niloticus) shows telomeric repeat tracts extending for 4-10 kb [Chew et al., 2002], while telomere length in medaka (Oryzias latipes) oscillates from 3 to $12 \mathrm{~kb}$ [Elmore et al., 2008]. Telomeres more similar in length to the average vertebrate telomeres are observed in the rainbow trout, dogfish shark (Squalus acanthias), little skate (Raja erinacea), and American eel (Anguilla rostrata) [Lejnine et al., 1995; Elmore et al., 2008]. The adult zebrafish (Danio rerio) have been shown to possess telomeres of about $16 \mathrm{~kb}$ [Anchelin et al., 2011] or even longer (20-25 kb) [Lund et al., 2009]. 
Table 1. Non-terminal location of the telomeric (TTAGGG) $)_{n}$ DNA sequences in fishes

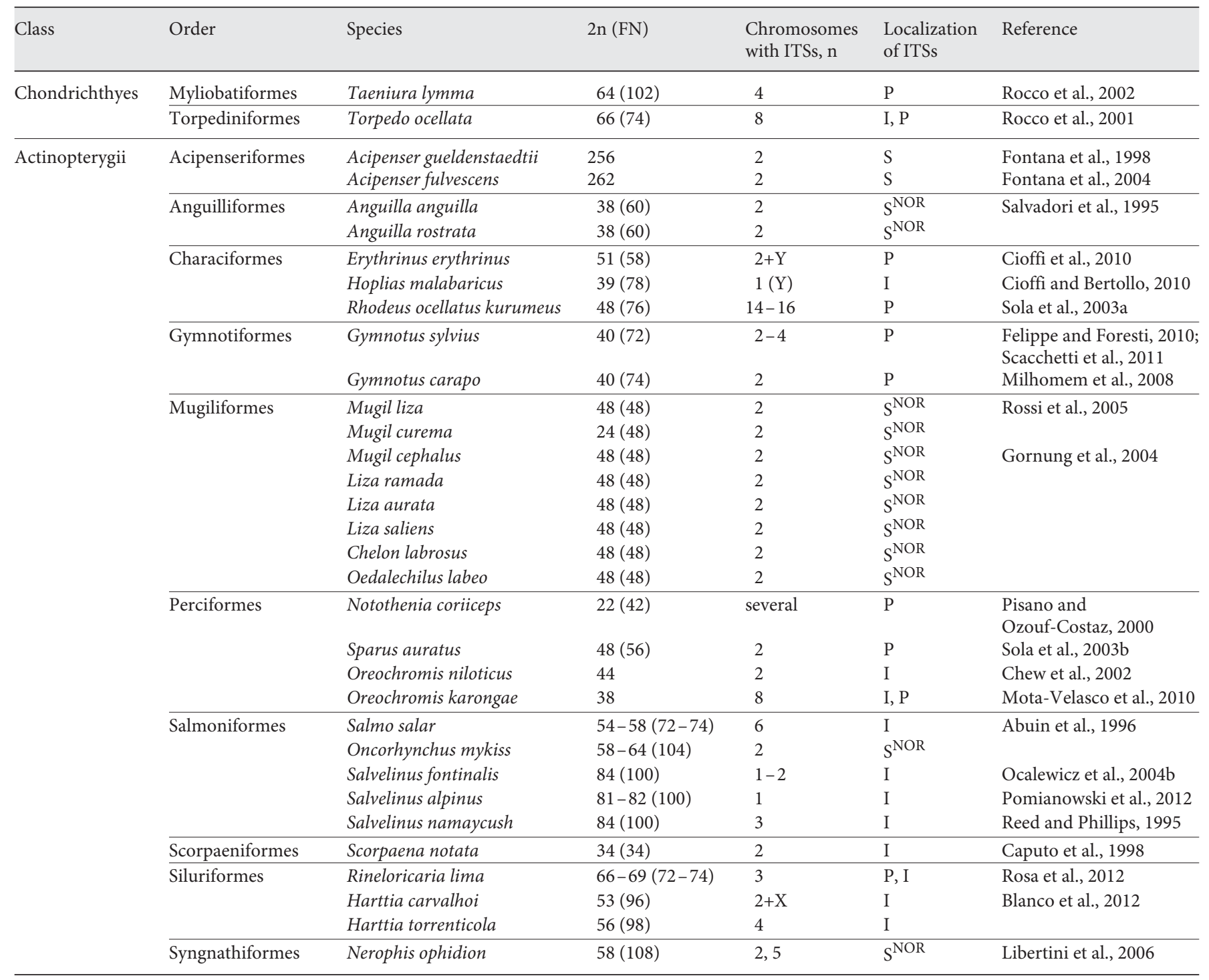

$\mathrm{FN}=$ Fundamental number; $\mathrm{I}=$ interstial (between telomeric and centromeric region); $\mathrm{P}$ = pericentromeric; $\mathrm{S}=$ scattered along the entire chromosomes; $\mathrm{S}^{\mathrm{NOR}}=$ scattered along the NORs.

In contrast to humans, where telomerase expression in adults is restricted to germ line cells, stem cells and tumors, expression of telomerase in various fish species has been detected in many tissues irrespective of the fish age [Klapper et al., 1998; Elmore et al., 2008; Hartman et al., 2009; Lund et al., 2009]. In recent studies, telomerase expression in fishes was shown to be upregulated during the regeneration of the injured tissues [Elmore et al., 2008; Anchelin et al., 2011]. However, as far as the relationship between telomerase expression and the fish regeneration capacity has been revealed, the role of telomerase in retention of the telomere length throughout the fish's entire life is not fully understood. Telomere shortening with age has been observed in medaka (O. latipes) and in the long-lived strain of the turquoise killifish (N. furzeri) [Hatekeyama et al., 2008; Hartmann et al., 2009]. However, such telomere attrition has not been detected in the short-lived strain of the killifish and in the wild-type zebrafish [Hartmann et al., 2009; Lund et al., 2009]. On the contrary, in the zebrafish individuals from another stock, the telomere length has been observed to increase from larvae to the adult fish and shorten significantly in the aged individuals [Anchelin et al., 2011]. 


\section{Chromosomal Distribution of the Telomeric DNA Sequences}

In fish, the chromosomal distribution of the telomeric DNA sequences is described in approximately 74 rayfinned species (Actinopterygii), 1 lobe-finned fish (Sarcopterygii) [Moreschalchi et al., 2002] and 4 cartilaginous fishes (Chondrichthyes) [Rocco et al., 2001, 2002]. Among actinopterygians, chromosomal location of the telomeric DNA repeats has been examined in the Chondrostei species from 2 orders: Acipenseriformes [Fontana et al., 1998, 2004, 2008] and Polypteriformes [Moreschalchi et al., 2007, 2008]. Within ray-finned fish of the infraclass Teleostei, the chromosomal distribution of the telomeric DNA sequences has been studied in fish species belonging to 15 orders: Anguilliformes [Salvadori et al., 1995], Batrachoidoformes [Merlo et al., 2007], Characiformes [de Marco Ferro et al., 2003; Cioffi et al., 2010], Cypriniformes [Meyne et al., 1990; Gornung et al., 1998; Sola et al., 2003a; Ocalewicz et al., 2004a; Gromicho et al., 2006; Schmid et al., 2006], Gasterosteiformes [Ocalewicz et al., 2011], Gymnotiformes [Milhomem et al., 2008; Silva et al., 2009; Felippe and Foresti, 2010; Scacchetti et al., 2011], Mugiliformes [Gornung et al., 2004; Rossi et al., 2005], Osmeriformes [Ocalewicz et al., 2007], Perciformes [Mandrioli et al., 2000; Sola et al., 2000, 2003b; Chew et al., 2002; Molina and Galetti, 2002; Mota-Velasco et al., 2010; Wang et al., 2010; Jacobina et al., 2011; Ocalewicz and Sapota, 2011; Jankun et al., 2013], Pleuronectiformes [Cross et al., 2006; Ocalewicz et al., 2008a], Salmoniformes [Reed and Phillips, 1995; Abuin et al., 1996; Ocalewicz et al., 2004b, 2008b; Jankun et al., 2007; Pomianowski et al., 2012], Scorpaeniformes [Caputo et al., 1998], Siluriformes [Margarido and Moreira-Filo, 2008; Rosa et al., 2012; Blanco et al., 2013], Syngnathiformes [Libertini et al., 2006], and Tetraodontiformes [Mandrioli et al., 1999; Fisher et al., 2000]. In all of these fish species, telomeric DNA sequences were observed at the very ends of all chromosomes including supernumerary B chromosomes [de Marco Ferro et al., 2003; Schmid et al., 2006]. In several fishes, interchromosomal variation in the intensity of the fluorescence signals after hybridization with the telomeric probe has been detected [Rocco et al., 2002; Ocalewicz and Dobosz, 2009; Pomianowski et al., 2012]. The differences in the telomere hybridization signal intensity observed on the different chromosomes are likely related to the variations in their respective telomere lengths [Landsorp et al., 1996]. In the albino rainbow trout, length polymorphism of the $\mathrm{p}$ arm of the $\mathrm{X}$ chromosome was observed and 2 morphs of the X chro- mosome were described. FISH with peptide nucleic acid telomeric probe exhibited weak hybridization spots on the $\mathrm{p}$ arm of the $\mathrm{X}$ chromosome short morph $\left(\mathrm{X}^{\mathrm{S}}\right)$ when compared to the distinct hybridization spots displayed on the $\mathrm{p}$ arm of the $\mathrm{X}$ chromosome long morph $\left(\mathrm{X}^{\mathrm{L}}\right)$ (fig. 1a, b). Differences in the telomere hybridization signal intensity observed between $\mathrm{p}$ arms of the $\mathrm{X}^{\mathrm{S}}$ and $\mathrm{X}^{\mathrm{L}}$ chromosomes may reflect variations in their telomere lengths. The faint telomeric signal detected on the $\mathrm{X}$ chromosome morph with a reduced short $\operatorname{arm}\left(\mathrm{X}^{S}\right)$ indicates an interstitial deletion of the chromatic segment with one of the breakpoints located within the telomeric region [Ocalewicz and Dobosz, 2009].

Apart from the terminal locations, additional non-terminal sites of the telomeric fluorescence hybridization spots are observed in about 33 fish species (table 1). The number of the chromosomes showing ITSs varies from 1 to 16 (table 1). Although such ITS sites are usually detected in the autosomes, ITS on the fish sex chromosomes have also been described (table 1). Based on the chromosomal locations of the non-terminal telomeric DNA sequences in fishes, we differentiate 4 main groups of such sites: (1) telomeric DNA sequences located at the pericentromeric regions, (2) interstitial telomeric sites observed between centromeres and the real telomeres (fig. 1), (3) telomeric DNA scattered along nucleolus organizer regions (NORs), and (4) telomeric DNA repeats interspersed with the entire chromosomes (table 1).

\section{Pericentromeric and Interstitial Telomeric DNA \\ Sequences}

Inactivation or physical elimination of the telomeres may lead to chromosome fusions [Slijepcevic, 1998]. If the telomeres lost their functions but remained at the chromosomal ends, fused chromosomes might show telomeric repeats at the fusion point. Thus, both pericentromeric and interstitial telomeric sites are usually considered as relicts of the ancient chromosomal rearrangements, namely centric fusions and tandem fusions, respectively [Meyne et al., 1990]. ITSs have been observed in many mammalian and non-mammalian species, showing more degenerative karyotypes when compared to their plesiomorphic (ancestral) complements [Meyne et al., 1990]. The karyotype, consisting of 48 uni-armed chromosomes, $(\mathrm{FN}=48)$ is supposed to be the ancestral karyotype in the Teleostei fishes [Ohno, 1970]. None of the teleostean species with telomeric DNA sequences detected at pericentromeric locations show such a karyotypic pattern (table 1). Two interstitial telomeric sites have been detected in the Nile tilapia (O. niloticus) $(2 \mathrm{n}=$ 
Fig. 1. Albino rainbow trout (Oncorhynchus mykiss) metaphase spread with 2 morphs of the $\mathrm{X}$ chromosome (arrowheads) after DAPI staining (a) and PNAFISH with telomeric probe (b). Green arrowheads show the long morph of the $\mathrm{X}$ chromosome $\left(\mathrm{X}^{\mathrm{L}}\right)$ with a distinct $\mathrm{p}$ arm and strong telomeric signals. Purple arrowheads indicate the short morph of the $\mathrm{X}$ chromosome $\left(\mathrm{X}^{\mathrm{S}}\right)$ with a reduced $\mathrm{p}$ arm and weak telomeric signals. ITSs (arrow) identified in the brook trout (Salvelinus fontinalis) (c) and the Arctic charr (S. alpinus) (d) chromosomes after PNA-FISH with telomeric probe. Scale bars $=10 \mu \mathrm{m}$.
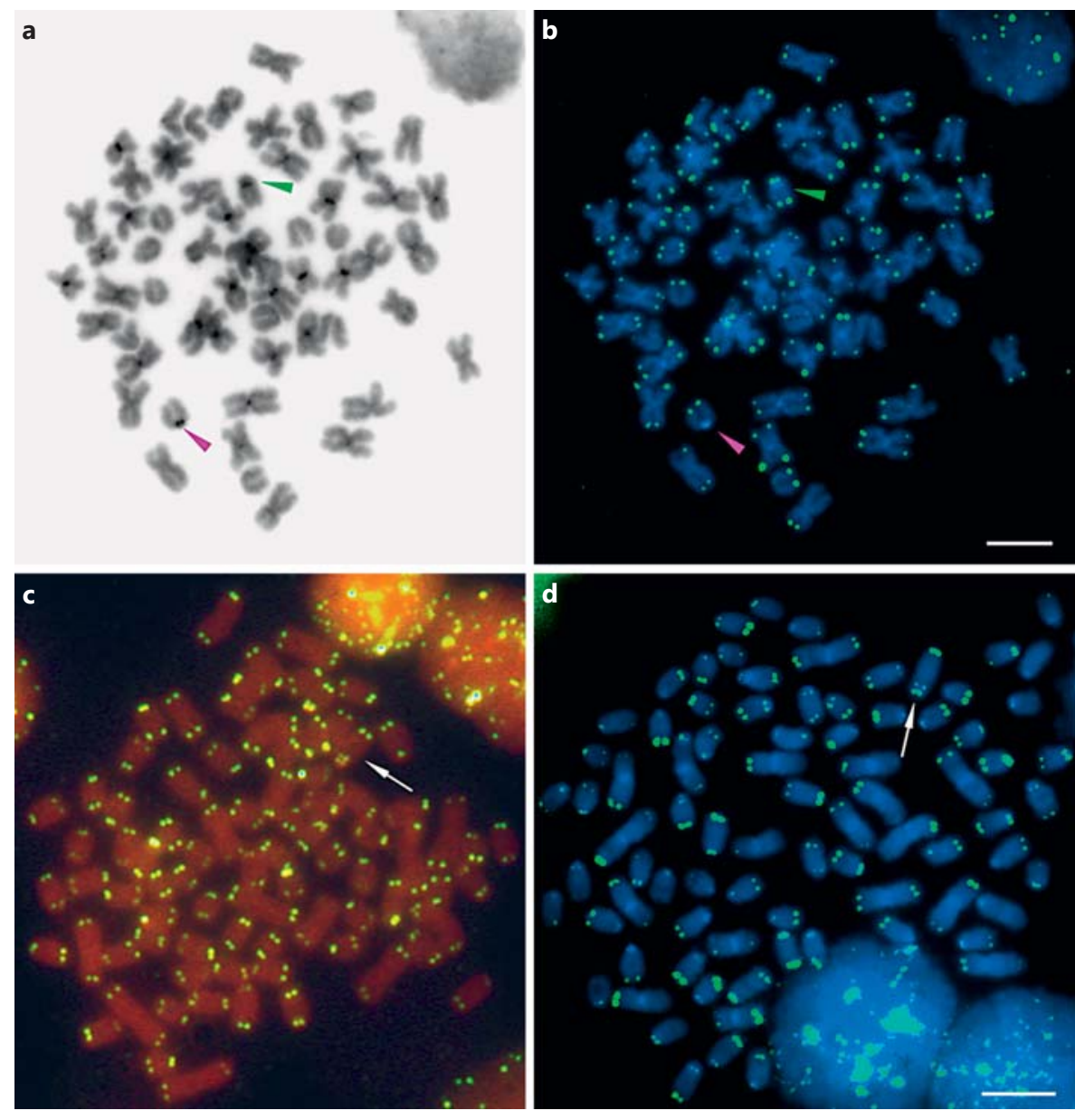

44) chromosome 1 that is significantly larger than all the other chromosomes in this organism [Chew et al., 2002]. This observation supported the hypothesis that chromosome 1 in the Nile tilapia appeared in the course of the fusion of 3 chromosomes and explained the reduction of the chromosome number of the ancestral cichlid karyotype from $2 \mathrm{n}=48$ to $2 \mathrm{n}=44$ [Chew et al., 2002]. In Oreochromis karongae, the diploid chromosome number is reduced to 38. The presence of 3 medium-sized chromosomes and the absence of 6 small chromosomes in the $O$. karongae karyotype, when compared to the Nile tilapia, suggest that the medium-sized chromosomes (2, 3 and 4) originated from fusion [Harvey et al., 2002]. The occurrence of the ITS sites on all 3 of these chromosomes confirms this assumption. The position of the current and relict centromeres and ITS sites in $O$. karongae suggests that the 3 fusions all occurred in different orientations [Mota-Velasco et al., 2010]. Two ITSs have also been observed in chromosome 1 of $O$. karongae that has been cor- roborated to share the homology with the largest chromosome pair in the Nile tilapia [Ocalewicz et al., 2009b; Mota-Velasco et al., 2010]. In the Erythrinidae family, 2n $=54$ is the most frequently observed chromosome number. The chromosome number reduction from 54 to 52/51 (females/males) observed in the Erythrinus erythrinus fish has been attributed to the centric fusions of the non-homologous acrocentric chromosomes. ITSs sites observed at the pericentromeric regions of 2 submetacentric chromosomes and the metacentric Y chromosome are presumably relicts of such rearrangements [Cioffi et al., 2010]. In the Hoplias malabaricus karyomorph with a $\mathrm{X}_{1} \mathrm{X}_{2} \mathrm{Y}$ sex chromosome system, interstitially located telomeric repeats observed on the long arm of the neo-Y chromosome may be a 'footprint' of the tandem fusion between the ancestral Y chromosome and one of the autosomes [Cioffi and Bertollo, 2010]. In the cartilaginous fishes that are considered as the ancient vertebrates, 2 species (Taeniura lymma and Torpedo ocellata) show 
pericentromeric location of telomeric DNA sequences detected on 4 bi-armed chromosomes [Rocco et al., 2001, 2002]. This is in agreement with the hypothesis that in cartilaginous fish, karyotype evolution involved a progressive decrease of the chromosome number due to chromosomal fusions [Rocco et al., 2001, 2002].

In fishes, as in other vertebrate species, pericentromeric ITSs are usually observed within or at the margin of the constitutive heterochromatin (positive C-band) [e.g. Meyne et al., 1990; Go et al., 2000; Milhomem et al., 2008; Cioffi et al., 2010; Scacchetti et al., 2011; Rosa et al., 2012]. This coincidence enabled Ruiz-Herrera et al. [2008] to describe such sites as heterochromatic ITSs (het-ITSs). The authors suggested a 4-step mechanism to explain the presence of such sites in the fused chromosomes: (1) The first step is the initial fusion event without loss of the telomeric sequences from the fusion site. (2) The next step is the formation of the (peri)centromeric heterochromatin by expansion of the internally located telomeric arrays including amplification of the telomeric sequences and other repeats. (3) Subsequently, the heterochromatic ITSs may be reorganized via chromosomal rearrangements resulting in the redistribution of the telomeric DNA, degeneration of the original ITS array, gradual shortening of the array, and even loss of the ITS. (4) Finally, the breakage within the heterochromatic ITS site may result in chromosome fissions [Ruiz-Herrera et al., 2008].

Not all chromosome fusions occur with retention of the telomeric DNA repeats at the fusion points [Garagna et al., 1995; Nanda et al., 1995]. The lack of the telomeric hybridization signals at the putative fusion sites may suggest that chromosome breakage preceding the fusion event occurred within the chromatin proximal to the telomeric region. On the other hand, telomeric repeats retained at the fusion sites might have experienced successive loss and degeneration leading to gradual shortening of the non-functional telomeric arrays [Slijepcevic, 1998]. Consequently, internally located telomeric repeats that are too short may be below the resolution of the techniques enabling chromosomal localization of the DNA sequences. The teleostean ancestral-like karyotype is also considered as basal in Scorpeanidae fishes; however, in Scorpaena notata, only 34 uni-armed chromosomes $(\mathrm{FN}=34)$ are observed. In this case, series of tandem fusions might be responsible for the chromosome and chromosome arm number reduction from 48 to 34 . Nevertheless, only one pair of $S$. notata chromosomes showed ITSs at the putative fusion sites [Caputo et al., 1998]. Chromosomal rearrangements such as centric and tandem fusions have played an important role in the salmonid karyotype evolution during the rediploidization process following the whole genome duplication event that occurred in the salmonid ancestor 100-25 Mya [Allendorf and Thorgaard, 1984]. The first tetraploid salmonid ancestor is thought to have 96 uni-armed chromosomes [Phillips and Ráb, 2001]. This karyotype underwent multiple chromosomal rearrangements leading to the formation of many different karyotypes composed of both biarmed and uni-armed chromosomes in which the diploid numbers vary from 52 to 102 ( $\mathrm{FN}=72-168)$ [Phillips and Ráb, 2001]. However, so far the only fused chromosomes which retained telomeric sequences at the fusion points have been observed in the Atlantic salmon karyotype [Abuín et al., 1996]. The diploid chromosome number in the knifefish (Gymnotus sp.) ranges from $2 \mathrm{n}=40$ to $2 \mathrm{n}=$ 54. Although multiple rearrangements including chromosome fusions are considered to be responsible for such variation, presently, pericentromeric locations of the telomeric DNA repeats have been found only in the most derived karyotypes $(2 \mathrm{n}=40)$ described in Gymnotus sylvius [Scacchetti et al., 2011] and in G. carapo [Milhomem et al., 2008]. Similarly, among several fused metacentric chromosomes described in the Rineloricaria lima, siluriform species with diploid chromosome numbers varying from 66 to 70, only 2 such chromosomes show telomeric DNA sequences at the fusion sites [Rosa et al., 2012].

A puzzling observation has been made in the bitterlings (Acheilognathinae). Two species, the Japanese bitterling (Rhodeus ocellatus kurumeus) and the oily bitterling (Tanakia limbata), sharing the same type of the karyotype that comprises 8 metacentric, 20 submetacentric and 20 subtelocentric chromosomes, show different distribution patterns of the telomeric hybridization signals. In the Japanese bitterling, interstitial telomeric sites were observed in the pericentromeric regions of 14-16 chromosomes, whereas in the oily bitterling, telomeric DNA sequences were confined to the chromosomal ends [Sola et al., 2003a]. If the ITSs occurred in the ancestor of both bitterlings, then such internally located telomeric DNA repeats had to evolve in different ways after divergence of these species.

Nevertheless, internally located telomeric repeats do not necessarily need to be the remnants of any ancient chromosomal rearrangements. Previously, several authors suggested that telomeric or telomeric-like DNA sequences were components of the satellite DNA in some vertebrates including fish [Garrido-Ramos et al., 1998]. Unexpectedly, the location of ITSs has been described in the conserved karyotypes of the American hylid frogs [Wiley et al., 1992], Xenopus laevis [Meyne et al., 1990, 
Nanda et al., 2008] and X. clivii [Nanda et al., 2008]. Homogeneity of the karyotypes among related species excluded chromosome fusions as the potential source of ITSs. ITSs in some of the marsupial mammals with the plesiomorphic complements $(2 \mathrm{n}=14)$ are suggested to be members of the native satellite DNA rather than relicts of the recent chromosome rearrangements [Metcalfe et al., 2004].

\section{Interstitial Telomeric DNA Sequences and the NORs}

ITSs are also observed in the vicinity of the NORs or even coincide with the NORs. Three Salvelinus species: lake trout (S. namaycush), brook trout (S. fontinalis) and the Arctic charr (S. alpinus), show subterminal positions of the ITSs assigned to the vicinity of the NOR-related $\mathrm{CMA}_{3}$-positive GC-rich heterochromatin [Reed and Phillips, 1995; Ocalewicz et al., 2004b; Pomianowski et al., 2012]. G-rich chromosomal regions are involved in several rearrangements resulting in multichromosomal locations and variations in size of the $\mathrm{CMA}_{3}$ positively stained chromatin in Salvelinus species [Phillips et al., 1988; Phillips and Ráb, 2001]. Dispersion of the GC-rich chromatin among homologous and non-homologous chromosomes could be followed by the insertion of the telomeric repeats linked to the translocated fragment into the interstitial position. In the case of the Arctic charr metaphase spreads showing extended chromatin, the non-telomeric fluorescence hybridization signal covered a longer stretch of the chromosome than the signal from the telomere position; however, the interstitial signal was less intense. This observation suggested that telomeric regions and ITS might have different structures [Pomianowski et al., 2012]. It is possible that telomeric DNA sequences were not the only component of the ITS region. Internally inserted short telomeric repeats are frequently flanked by the repetitive or transposable elements and undergo an amplification process, leading to elongation/ expansion of the chromatic region built with different DNA sequences including telomeric repeats [GarridoRamos et al., 1998]. ITSs are also considered as sites that are able to promote recombination, and thus, they may potentially increase the rates of chromosome breaks and rearrangements [Lin and Yan, 2008]. This could partially explain the high level of size and location polymorphisms of the NOR regions in Salvelinus species [Phillips et al., 1988; Phillips and Ráb, 2001; Pomianowski et al., 2012].

Telomeric DNA sequences are observed to scatter along the NORs in 12 fish species belonging to Anguilliformes, Mugiliformes, Salmonifromes, and Syngnathiformes (table 1). In the mullets (Mugiliformes, Mugili- dae), co-localization of the telomeric repeats and major rDNA sequences seems to be a common pattern [Gornung et al., 2004; Rossi et al., 2005] (table 1). Similar location of the telomeric repeats has been previously described in the mammalian and amphibian species [Meyne et al., 1990; Liu and Fredga, 1999; Zhdanova et al., 2007; Nanda et al., 2008]. Although the origin and function of the telomeric repeats interspersed with the rDNA sequences are unclear, it has been suggested that such located telomeric arrays play some role in the nucleolus formation. On the other hand, ribosomal repeats co-localized with the telomeric sequences can stabilize broken chromosomal ends [Pich et al., 1996; Liu and Fredga, 1999]. Telomeres may silence genes located in their vicinity. Such a phenomenon is called a 'telomere position effect' [Gottschling et al., 1990]. Thus, it is reasonable to assume that ITSs observed in the vicinity of NORs or interspersed with the major rDNA sequences may epigenetically inactivate NORs [Guillén et al., 2004].

\section{Telomeric DNA Repeats Interspersed with the Entire Sturgeon Microchromosomes}

The karyotypes of the Acipenseriformes (sturgeons and paddlefishes) are characterized by a large number of chromosomes, about half of which are microchromosomes. In the Russian sturgeon (Acipenser gueldenstaedtii) and in the lake sturgeon (A. fulvescens), 2 entire microchromosomes showed bright fluorescence signals derived from the telomeric probe [Fontana et al., 1998, 2004]. Similar distribution patterns of the hybridization signals have been described in some of the bird and reptile microchromosomes [Nanda et al., 2002; Srikulnath et al., 2011]. To intersperse with the entire microchromosomes, telomeric DNA sequences must have undergone extensive amplification processes extending telomeric arrays to an exceptional length ranging from $40 \mathrm{~kb}$ to $2 \mathrm{Mb}$ or even longer [Delany et al., 2000]. As telomeric DNA sequences may promote recombination processes, their abundance may explain the enormously high recombination rate observed in the avian microchromosomes [Nanda et al., 2002].

\section{Distribution of Telomeric DNA Sequences on the Radiation-Induced Chromosome Fragments in Fish}

Ionizing radiation ( $\gamma$-and $\mathrm{X}$-rays) is a strong physical mutagen that may damage chromosomal DNA by inducing DSB. Misrepaired ionizing radiation-induced damages frequently lead to various chromosome aberrations 
including, for example, dicentric chromosomes, centric rings or acentric linear fragments. [Hlatky et al., 2002]. The damaging feature of the ionizing radiation makes it suitable for inactivation of the nuclear DNA in the fish gametes during the process of artificially induced gynogenesis and androgenesis to deliver specimens possessing only maternal or paternal nuclear DNA, respectively. Gynogenetic and androgenetic fish are produced in the course of a 3-step process: irradiation of spermatozoa (gynogenesis) or eggs (androgenesis), insemination, and diploidization of the maternal or paternal chromosomes. The last step is achieved by the exposure of the haploid zygotes to the thermal or hydrostatic pressure shock inhibiting the release of the second polar body (heterozygous gynogenesis) or suppressing the first mitotic division of the zygote (homozygous gynogenesis and androgenesis) [Pandian and Koteeswaran, 1998]. A low radiation dose may result in the incomplete damaging of the nuclear genome. Undamaged pieces of the irradiated chromosomes may retain in the gynogenetic and androgenetic specimens as radiation-induced chromosome fragments [Chourrout and Quillet, 1982; Ocalewicz et al., 2004c]. As such fragments are usually much smaller than the smallest intact chromosomes, it was very difficult to define their morphology until application of FISH with the telomeric probe (fig. 2a) [Ocalewicz et al., 2004c, 2007, 2012]. Distribution patterns of the telomeric hybridization signals on the rainbow and brook trout ionizing radiation-induced chromosome fragments led to the discrimination of several groups: (1) linear chromosome fragments with telomeric DNA sequences at both ends, (2) ring chromosomes with fused, broken chromosome arms showing no telomeric signals, (3) ring chromosomes formed in the course of fusion of the radiationbroken chromosome arms with the opposite telomeric region and displayed interstitial telomeric signals at the fusion point, and (4) radiation-induced chromosome fragments with 2 telomeric signals observed in only one arm (fig. 2b-e) [Ocalewicz et al., 2007, 2012]. Moreover, ITSs observed on several androgenetic rainbow trout chromosomes suggest that radiation-induced chromosome fragments of maternal origin may incorporate into the paternal chromosomes (fig. 2f) [Ocalewicz et al., 2004c]. Fragments with the chromosome breaks on both sides of the centromere form ring chromosomes, presumably in the course of non-homologous end joining repair [e.g. Pfeifer et al., 2004]. On the other hand, the broken ends of the chromosomes could have been repaired with the telomeric DNA repeats synthesized de novo by telomerase or another mechanism capable of de
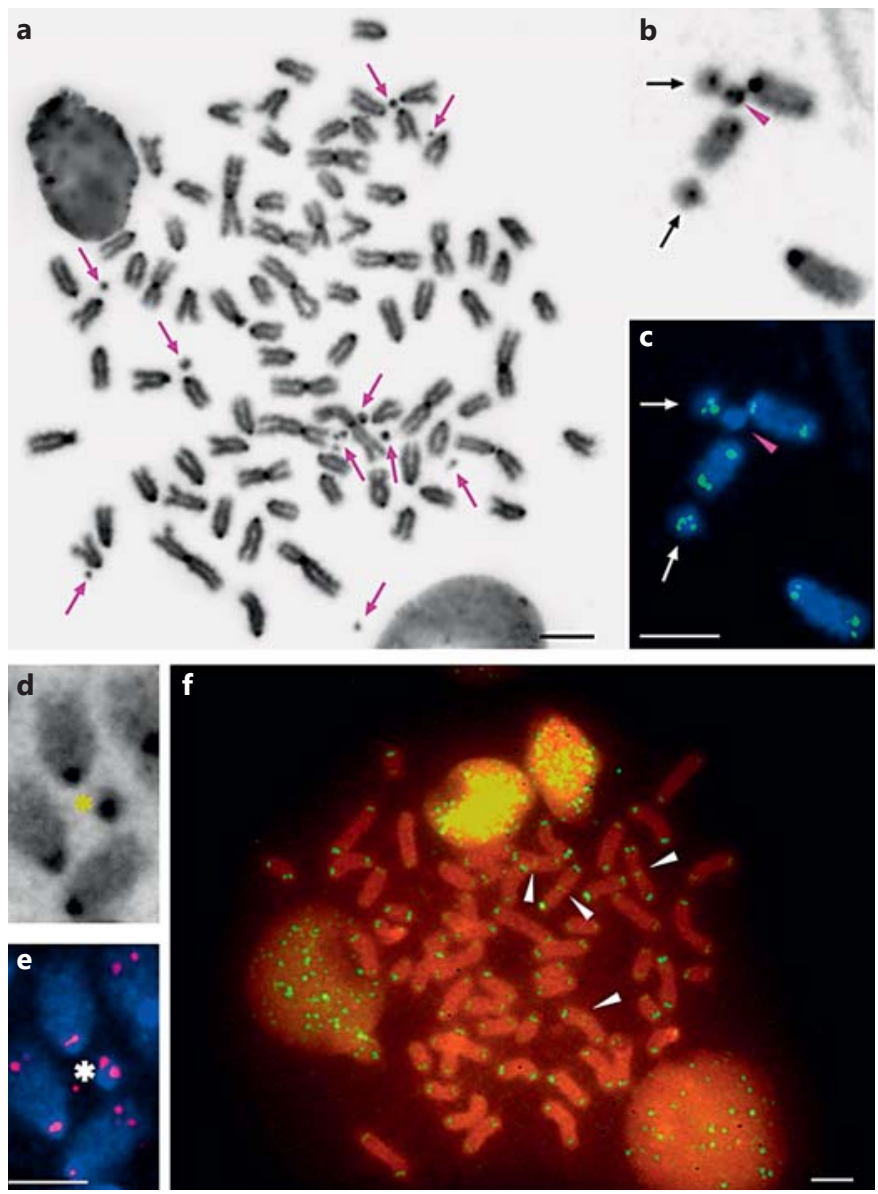

Fig. 2. Mitotic chromosomes of the androgenetic fish. X-radiationinduced fragments of maternal chromosomes (purple arrows) observed in the androgenetic brook trout (S. fontinalis) (a). Partial metaphase spreads of the androgenetic brook trout $\times$ Arctic charr (S. alpinus) hybrids, including telomerless ring chromosome fragments (purple arrowheads) (b, c), linear fragments (arrows) (b, c) and chromosome fragments with fused sister chromatids and 2 telomeric signals present in only one arm (asterisks) (d, e) after DAPI staining $(\mathbf{a}, \mathbf{b}, \mathbf{d})$, PNA-FISH with telomeric probe (c) and PRINS with (CCCTAA) 7 primer (e). ITSs observed on the androgenetic rainbow trout (O. mykiss) chromosomes (white arrowheads) after PNA-FISH with telomeric probe (f). Scale bars $=5 \mu \mathrm{m}$.

novo telomere addition [Biessmann et al., 1990] and retain the linear construction [Ocalewicz et al., 2000a]. The rings with 2 interstitially located telomeric signals described in the androgenetic brook trout might have also been formed in the course of fusion of the radiation-broken chromosome arm with the opposite unbroken arm or arm broken within the telomeric region [Henegariu et al., 1997]. However, we do not exclude that this fragment might have originated from one of the brook trout chro- 
mosomes with the ITSs [Ocalewicz et al., 2004b]. Chromosome fragments showing 2 always terminally located telomeres represented another chromatin arrangement. The shape and distribution of the hybridization spots suggested the telomere loss in only one chromosome arm and the fusion between sister chromatids.

Although telomerase is capable to heal broken ends of the irradiated fish chromosomes, most of the fragments found in the androgenetic fish show a spherical shape. For instance, it is possible that fish telomerase is not always able to heal the broken chromosome ends with the newly synthesized telomeric DNA due to the limited access to the DNA breaks [Latre et al., 2004]. However, telomerase in fish seems to be involved in the DSB repair, which is in agreement with the observations made in the mammalian genomes [Ruiz-Herrera et al., 2008].

\section{Conclusions}

There are several reasons to consider fish as model animals in studies concerning genomic organization of the telomeric DNA sequences and expression of the telomerase. As the DNA component of the telomeres is conserved among vertebrates, chromosomal distribution and length of the telomeric repeats in fish may be studied with the help of widely available molecular tools already accepted for similar research performed in other vertebrates. The length of the telomeric DNA sequences in most of the fish species studied to date is similar to the telomere length observed in the normal human cells. Moreover, in some of the fish species, telomere shortening with age has also been observed. Less than half of about 80 fish species studied to date show telomeric DNA sequences located far from the chromosomal ends. Such non-terminally located telomeric repeats in fish are usually observed at the pericentromeric regions and between centromeres and the real telomeres. (TTAGGG) ${ }_{\mathrm{n}}$ sequences may be also interspersed with the entire fish chromosomes or their particular segments like NORs. Most of the ITSs detected in the fish genome appeared in the course of the rearrangements that are responsible for the ITSs formation in the higher vertebrates. Although telomerase has been shown to be expressed in most cells throughout the fish's entire life, no positive relationship between telomerase activity and the fish longevity has been confirmed. On the other hand, it has been proven that telomerase in fish plays an important role in maintaining telomere length during regeneration of the injured tissues. Telomerase in fish might also be involved in the process of ionizing radiation-induced DNA DSBs repair.

\section{Acknowledgements}

I would like to thank the Guest Editor and 2 anonymous reviewers for their valuable comments and suggestions on the manuscript. This work was supported in part by the National Science Centre (Poland), grant NN311525240.

\section{References}

-Abuín M, Martínez P, Sánchez L: Localization of the repetitive telomeric sequence(TTAGGG) in four salmonid species. Genome 39:10351038 (1996).

Allendorf FW, Thorgaard GH: Tetraploidy and the evolution of salmonid fishes, in Turner BJ (ed): Evolutionary Genetics of Fishes (Plenum Press, New York 1984).

-Anchelin M, Murcia L, Alcarez-Pérez F, GarcíaNavarro EM, Cayuela ML: Behaviour of telomere and telomerase during aging and regeneration in zebrafish. PLoS One 6:e16955 (2011).

-Ashley T, Ward DC: A 'hot spot' of recombination coincides with an interstitial telomeric sequences in Armenian hamster. Cytogenet Cell Genet 62:169-171 (1993).

-Biessmann H, Mason JM: Telomere maintenance without telomerase. Chromosoma 106:63-69 (1997).

-Biessmann H, Mason JM, Ferry K, d'Hulst M, Valgeirsdottir K, et al: Addition of telomere- associated HeT DNA sequences 'heals' broken chromosome ends in Drosophila. Cell 61: 663-673 (1990).

Blanco DR, Vicari MR, Lui RL, Bertollo LAC, Traldi JB, Moreira-Filho O: The role of the Robertsonian rearrangements in the origin of the $\mathrm{XX} / \mathrm{XY}_{1} \mathrm{Y}_{2}$ sex chromosome system and in the chromosomal differentiation in Harttia species (Siluriformes, Loricariidae). Rev Fish Biol Fisheries 23:127-134 (2013).

Bolzán AD, Bianchi MS: Telomeres, interstitial telomeric repeat sequences, and chromosomal aberrations. Mutat Res 612:189-214 (2006).

Caputo V, Sorice M, Vitturi R, Magistrelli R, Olmo E: Cytogenetic studies in some species of Scorpaeniformes (Telesotei: Percomorpha). Chromosome Res 6:255-262 (1998).

Chew JSK, Oliveira C, Wright JM, Dobson MJ: Molecular and cytogenetic analysis of the telomeric (TTAGGG) ${ }_{\mathrm{n}}$ repetitive sequences in the Nile Tilapia, Oreochromis niloticus (Teleostei: Cichlidae). Chromosoma 111:45-52 (2002).
Chourrout D, Quillet E: Induced gynogenesis in rainbow trout: sex and survival of progenies production of all triploid populations. Theor Appl Genet 63:201-205 (1982).

Cioffi MB, Bertollo LAC: Initial steps in XY chromosome differentiation in Hoplias malabaricus and the origin of an $\mathrm{X}_{1} \mathrm{X}_{2} \mathrm{Y}$ sex chromosome system in this fish group. Heredity (Edinb) 105:554-561(2010).

-Cioffi MB, Martins C, Bertollo LAC: Chromosome spreading of associated transposable elements and ribosomal DNA in the fish Erythrinus erythrinus. Implications for genome change and karyoevolution in fish. BMC Evol Biol 10:271 (2010).

Cross I, Merlo A, Manchado M, Infante C, Cañavate JP, Rebordinos L: Cytogenetic characterization of the sole Solea senegalensis (Telesotei: Pleuronectiformes: Soleidae): Ag-NOR, $(\text { GATA })_{n}(\text { TTAGGG })_{n}$ and ribosomal genes by one-color and two-color FISH. Genetica 128:253-259 (2006). 
de Lange T: Protection of mammalian telomeres. Oncogene 21:532-540 (2002).

Delany ME, Krupkin AB, Miller MM: Organization of telomere sequences in birds: evidence for arrays of extreme length and for in vivo shortening. Cytogenet Cell Genet 90:139-145 (2000).

$\checkmark$ de Marco Ferro DA, Moreira-Filho O, Bertollo LA: B chromosome polymorphism in the fish, Astyanax scabripinnis. Genetica 119:147-153 (2003).

Downs KP, Shen Y, Pasquali A, Beldorth I, Savage $M$, et al: Characterization of telomeres and telomerase expression in Xiphophorus. Comp Biochem Phys C Toxicol Pharmacol 155:8994 (2012).

-Elmore LW, Norris MW, Sircab S, Bright T, McChesney PA, et al: Upregulation of telomerase function during tissue regeneration. Exp Biol Med (Maywood) 233:958-967 (2008).

Felippe CL, Foresti ATL: Evidence of chromosome fusion in Gymnotus sylvius Albert \& Fernandes-Matoli, 1999 (Teleostei: Gymnotiformes) detected by telomeric probes and Rbanding. Caryologia 63:13-141 (2010).

-Fisher C, Ozouf-Costaz C, Roest Crollius H, Dasilva C, Jaillon O, et al: Karyotype and chromosome location of characteristic tandem repeats in the pufferfish Tetraodon nigrovirids. Cytogenet Cell Genet 88:50-55 (2000).

-Fontana F, Lanfredi M, Chicca M, Aiello V, Rossi $\mathrm{R}$ : Localization of repetitive telomeric sequences (TTAGGG) $)_{\mathrm{n}}$ in four sturgeon species. Chromosome Res 6:303-306 (1998).

Fontana F, Bruch RM, Binkowski FP, Lanfredi M, Chicca M, et al: Karyotype characterization of the lake sturfeon, Acipenser fulvescens (Rafinesque 1817) by chromosome banding and fluorescent in situ hybridization. Genome 47 : 742-746 (2004).

Fontana F, Lanfredi M, Kirschbaum F, GarridoRamso MA, Robles F, et al: Comparison of karyotypes of Acipenser oxyrinchus and A. sturio by chromosome banding and fluorescent in situ hybridization. Genetica 132:281286 (2008).

Garagna S, Broccoli D, Redi CA, Searle JB, Cooke HJ, Capanna E: Robertsonian metacentrics of the mouse lose telomeric sequences but retain some minor satellite DNA in the pericentromeric area. Chromosoma 103:685-692 (1995).

Garrido-Ramos MA, de la Herrán R, Ruiz Rejón C, Ruiz Rejón M: A satellite DNA of Sparidae family (Pisces, Perciformes) associated with telomeric sequences. Cytogenet Cell Genet 83:3-9 (1998).

Go Y, Rakotoarisoa G, Kawamoto Y, Randrianjafy A, Koyama N, Hirai H: PRINS analysis of the telomeric sequences in seven lemurs. Chromosome Res 8:57-65 (2000).

Gornung E, Gabrielli I, Sola L: Localization of the (TTAGGG) $)_{n}$ telomeric sequences in zebrafish chromosomes. Genome 41:136-138 (1998).
Gornung E, Mannarelli ME, Rossi AR, Sola L: Chromosomal evolution in Mugilidae (Pisces, Mugiliformes): FISH mapping of the $(\text { TTAGGG })_{n}$ telomeric repeat in the six Mediterranean mullets. Hereditas 140:158-159 (2004).

-Gottschling DE, Aparicio OM, Billington BL, Zakian VA: Position effect at S. cerevisiae telomeres: reversible repression of Po lI transcription. Cell 63:751-762 (1990).

Gromicho M, Coelho MM, Alves MJ, CollaresPereira MJ: Cytogenetic analysis of the Anaecypris hispanica and its relationship with the paternal ancestor of the diploid-polyploid Squalius alburnoides complex. Genome 49: 1621-1627 (2006).

Guillén AKZ, Hirai Y, Tanoue T, Hirai H: Transcriptional repression mechanisms of nucleolus organizer regions (NORs) in human and chimpanzees. Chromosome Res 12:225-237 (2004).

-Hartmann N, Reichwald K, Lechel A, Graf M, Kirschner J, et al: Telomeres shorten while Tert expression increase during ageing of the short-lived fish Nothobranchius furzeri. Mech Ageing Dev 130:290-296 (2009).

- Harvey SC, Campos-Ramos R, Kennedy DD, Ezaz MT, Bromage NR, et al: Karyotype evolution in Tilapia: mitotic and meiotic chromosome analysis of Oreochromis karongae and $O$. niloticus $\times$ O. karongae hybrids. Genetica 115:169-177 (2002).

-Hatekeyama H, Nakamura K, Izumijama-Shimomura N, Ishii A, Tsuchida S: The teleost Oryzias latipes shows telomere shortening with age despite considerable telomerase activity throughout life. Mech Ageing Dev 129:550557 (2008).

Henegariu O, Kernek S, Keating MA, Palmer CG, Heerema NA: PCR and FISH analysis of a ring Y chromosome. Am J Med Genet 69:171-176 (1997).

-Hlatky L, Sachs RK, Vazquez M, Cornforth MN: Radiation-induced chromosome aberrations: insight gained from biophysical modelling. Bioessays 24:714-723 (2002).

-Jacobina UP, Cioffi MB, Souza LGR, Calado LL, Tavares M, et al: Chromosome mapping of repetitive sequences in Rachycentron canadum (Perciformes: Rachycentridae): implications for karyotypic evolution and perspectives for biotechnological uses. J Biomed Biotechnol 2011:218-231 (2011).

Jankun M, Woznicki P, Ocalewicz K, FurgalaSelezniow G: Chromosomal evolution in the three species of Holarctic fish of the genus Coregonus (Salmoniformes). Adv Limnol 60: 25-37 (2007).

Jankun M, Mochol M, Ocalewicz K: Conventional and molecular cytogenetics of the pikeperch (Sander lucioperca L.). Aquaculture Res DOI:10.1111/are.12047 (2013).

Kipling D, Cooke HJ: Hypervariable ultra-long telomeres in mice. Nature 347:400-402 (1990).

Klapper W, Heidorn K, Kühne K, Parwaresch R, Krupp G: Telomerase activity in 'immortal' fish. FESB Lett 434:409-412 (1998).
Lansdorp PPM, Verwoerd NP, van den Rijke FM, Dragowska V, Little MT, et al: Heterogeneity in telomere length of human chromosomes. Human Mol Genet 5:685-691 (1996).

- Latre L, Genesca A, Martin M, Ribas M, Egozcue J, et al: Repair of DNA broken ends is similar in embryonic fibroblass with and without telomerase. Radiat Res 162:136-142 (2004).

Lejnine S, Makarov VL, Langmore JP: Conserved nucleoprotein structure at the ends of vertebrate and invertebrate chromosomes. Proc Natl Acad Sci USA 92:2393-2397 (1995).

Libertini A, Vitturi R, Lannino A, Maone MC, Franzoi P, et al: Fish mapping of 18s rDNA and (TTAGGG) $)_{n}$ sequences in two pipefish species (Gasteroisteiformes: Syngnathidae). J Genet 85:153-156 (2006).

Lin KW, Yan J: Endings in the middle: current knowledge of interstitial telomeric sequences. Mutat Res 658:95-110 (2008).

Liu WS, Fredga K: Telomeric (TTAGGG) $)_{n}$ sequences are associated with nucleolus organizer regions (NORs) in the wood lemming. Chromosome Res 7:235-240 (1999).

-Londoño-Vallejo JA, DerSarkissian H, Cazes L, Thomas G: Differences in telomere length between homologous chromosomes in humans. Nucleic Acids Res 29:3164-3171 (2001).

-Ludérus MEE, van Steensel B, Chong L, Sibon OCM, Cremers FFM, de Lange T: Structure, subnuclear distribution, and nuclear matrix association of the mammalian telomeric complex. J Cell Biol 135:867-881 (1996).

Lund TC, Glass TJ, Tolar J, Blazer BR: Expression of telomerase and telomere length are unaffected by either age or limb regeneration in Danio rerio. PLoS One 4:e7688 (2009).

-Mandrioli M, Cuoghi B, Marini M, Manicardi G: Localization of the (TTAGGG) ${ }_{n}$ telomeric repeat in the chromosomes of the pufferfish $\mathrm{Te}$ traodon fluviatilis (Hamilton Buchanan) (Osteichthyes). Caryologia 52:155-157 (1999).

Mandrioli M, Colomba MS, Vitturi R: Chromosomal analysis of repeated DNAs in the rainbow wrasse Coris julis (Pisces, Labridae). Genetica 108:191-195 (2000).

Margarido VP, Moreira-Filho O: Karyotypic differentiation through chromosome fusion and number reduction in Imparfinis hollandi (Ostariophysi, Heptaperidae). Genet Mol Biol 31: 235-238 (2008).

-Merlo A, Cross I, Palazón JL, Sarasquete C, Rebrodinos L: Chromosomal mapping of the major and minor ribosomal genes, (GATA) and (TTAGGG) ${ }_{n}$ by one-color and doublecolor FISH in the toadfish Halobatrachus didactylus (Teleostei: Batrachoididae). Genetica 131:195-200 (2007).

- Metcalfe CJ, Eldridge MDB, Johnston PG: Mapping the distribution of the telomeric sequence $\left(\mathrm{T}_{2} \mathrm{AG}_{3}\right)_{\mathrm{n}}$ in the $2 \mathrm{n}=14$ ancestral marsupial complement and in the macropodines (Marsupialia: Macropodidae) by fluorescence in situ hybridization. Chromosome Res 12: 405-414 (2004). 
Meyne J, Ratliff RL, Moyzis RK: Conservative of the human telomere sequences (TTAGGG) among vertebartes. Proc Natl Acad Sci USA 86:7049-7053 (1989).

-Meyne J, Baker R, Hobart HH, Hsu TC, Ryder OA, et al: Distribution of non-telomeric sites of the $(\text { TTAGGG) })_{\mathrm{n}}$ telomeric sequence in vertebrate chromosomes. Chromosoma 99:3-10 (1990).

-Milhomem SR, Pieczarka JC, Crampton WGR, Dilva DS, De Souza ACP, et al: Chromosomal evidence for a putative cryptic species in the Gymnotus carapo species-complex (Gymnotiformes, Gymnotidae). BMC Genetics 9:75 (2008).

-Molina WF, Galetti PM Jr: Robertsonian rearrangements in the reef fish Chromis (Perciformes, Pomacentridae) involving chromosomes bearing 5S rRNA genes. Genet Mol Biol 25:373-377 (2002).

Moreschalchi MA, Rocco L, Stingo V: Cytogenetic and molecular studies in a lungfish, Protopterus annectus (Osteichthyes, Dipnoi). Gene 295:279-287 (2002).

Moreschalchi MA, Liguori I, Rocco L, Archimandritis A, Stingo V: Karyotypic characterization and genomic organization of the $5 \mathrm{~S}$ rDNA in Erpetoichthys calabaricus (Osteichthyes, Polypteridae). Genetica 131:209-216 (2007).

Moreschalchi MA, Liguori I, Rocco L, Archimandritis A, Stingo V: Karyotypic characterization and genomic organization of the $5 \mathrm{~S}$ rDNA in Polypterus senegalus (Osteichthyes, Polypteridae). Genetica 132:179-186 (2008).

Mota-Velasco JC, Alves Ferreira J, Cioffi MB, Ocalewicz K, Campos-Ramos R, et al: Characterization of the chromosome fusions in Oreochromis karongae. Chromosome Res 18:575586 (2010).

-Moyzis RK, Buckingham JM, Cram LS, Dani M, Deaven LL, et al: A highly conserved repetitive DNA sequence, (TTAGGG) , present at the telomeres of human chromosomes. Proc Natl Acad Sci USA 85:6622-6626 (1988).

Nanda I, Schneider-Rasp S, Winking H, Schmid M: Loss of telomeric sites in the chromosomes of Mus musculus domesticus (Rodentia: $\mathrm{Mu}-$ ridae) during Robertsonian rearrangements. Chromosome Res 3:399-409 (1995).

-Nanda I, Schrama D, Feichtinger W, Haaf T, Schartl M, Schmid M: Distribution of telomeric (TTAGGG) $)_{\mathrm{n}}$ sequences in avian chromosomes. Chromosoma 111:215-227 (2002).

- Nanda I, Fugate M, Steinlein C, Schmid M: Distribution of (TTAGGG) $)_{n}$ telomeric sequences in karyotypes of the Xenopus species complex. Cytogenet Genome Res 122:396-400 (2008).

- Nergadze SG, Santagostino MA, Salzano A, Mondello C, Giulotto E: Contribution of telomerase RNA retrotranscription to DNA doublestrand break repair during mammalian genome evolution. Genome Biol 8:R260 (2007).

-Ocalewicz K, Dobosz S: Karyotype variation in the albino rainbow trout (Oncorhynchus mykiss Walbaum). Genome 52:347-352 (2009).
Ocalewicz K, Sapota M: Cytogenetic characteristics of the round goby Neogobius melanostomus (Teleostei: Gobiidae: Benthophilinae). Mar Biol Res 7:195-201 (2011).

Ocalewicz K, Jankun M, Boron A: Karyotypic characterization of bream, Abramis brama (Pisces, Cyprinidae). Folia Zool 53:329-334 (2004a).

Ocalewicz K, Śliwińska A, Jankun M: Autosomal localization of internal telomeric sites (ITS) in brook trout, Salvelinus fontinalis (Pisces, Salmonidae). Cytogenet Genome Res 105:79-82 (2004b).

-Ocalewicz K, Babiak I, Dobosz S, Nowaczyk J, Goryczko K: The stability of telomereless chromosome fragments in adult androgenetic rainbow trout. J Exp Biol 207:2229-2236 (2004c).

-Ocalewicz K, Hliwa P, Krol J, Rábová M, Stabinski R, Ráb P: Karyotype and chromosomal characteristics of Ag-NOR sites and 5S rDNA in European smelt (Osmerus eperlanus). Genetica 131:29-35 (2007).

-Ocalewicz K, Penman DJ, Babiak I: Variation in size and location of the Ag-NOR in the Atlantic halibut (Hippoglossus hippoglossus). Genetica 133:261-267 (2008a).

-Ocalewicz K, Woznicki P, Jankun M: Mapping of rRNA genes and telomeric sequences in Danube salmon (Hucho hucho) chromosomes using primed in situ labeling technique (PRINS). Genetica 134:199-203 (2008b).

Ocalewicz K, Dobosz S, Kuzminski H, Goryczk K: Formation of chromosome aberrations in androgenetic rainbow trout (Oncorhynchus mykiss). J Fish Biol 75:2373-2379 (2009a).

-Ocalewicz K, Mota-Velasco JC, Campos-Ramos R, Penman DJ: FISH and DAPI staining of the synaptonemal complex of the Nile tilapia (Oreochromis niloticus) allow orientation of the unpaired region of bivalent 1 observed during early pachytene. Chromosome Res 17: 773-782 (2009b).

Ocalewicz K, Woznicki P, Furgala-Selezniow G, Jankun M: Chromosomal location of $\mathrm{Ag} /$ $\mathrm{CMA}_{3}$-NORs, 5S rDNA and telomeric repeats in two stickleback species. Ital J Zool 78: 12-19 (2011)

Ocalewicz K, Dobosz S, Kuzminski H: Distribution of telomeric DNA sequences on the Xradiation-induced chromosome fragments observed in the genome of androgenetic brook trout (Salvelinus fontinalis, Mitchill 1814). Cytogenet Genome Res 131:1-6 (2012).

O'Hare TA, Delany ME: Genetic variation exists for telomeric array organization within and among the genomes of normal, immortalized, and transformed chicken systems. Chromosome Res 17:947-964 (2009).

Ohno S: Evolution by Gene Duplication (Springer, New York 1970).

Olovnikov AM: A theory of marginotomy. The incomplete copying of template margin in enzymic synthesis of polynucleotides and biological significance of the phenomenon. J Theor Biol 41:181-190 (1973).
Pandian TJ, Koteeswaran R: Ploidy induction and sex control in fish. Hydrobiologia 384:167243 (1998)

-Pfeifer P, Goedecke W, Kuhfitting-Kulle S, Obe G: Pathways of DNA double-strand break repair and their impact on the prevention and formation of chromosomal aberrations. Cytogenet Genome Res 104:7-13 (2004).

Phillips RB, Ráb P: Chromosome evolution in the salmonidae (Pisces): an update. Biol Rev Camb Philos Soc 76:1-25 (2001).

Phillips RB, Pleyte KA, Hartley SE: Stock-specific differences in the number and chromosome positions of the nucleolar organizer regions in arctic charr (Salvelinus alpinus). Cytogenet Cell Genet 48:9-12 (1988)

Pich U, Fuchs J, Schubert I: How do Alliaceae stabilize their chromosome ends in the absence of TTTAGGG sequences? Chromosome Res 4:207-213 (1996).

Pisano E, Ozouf-Costaz C: Chromosome change and evolution in the Antarctic fish suborder Nothotenioidei. Antarct Sci 12:334-342 (2000).

Pomianowski L, Jankun M, Ocalewicz K: Detection of interstitial telomeric sequences in the Arctic charr (Salvelinus alpinus, Linnaeus 1758) (Teleostei, Salmonidae). Genome 55: 26-32 (2012).

Reed K, Phillips RB: Molecular cytogenetic analysis of the double-CMA3 chromosome of lake trout, Salvelinus namaycush. Cytogenet Cell Genet 70:104-107 (1995).

Rocco L, Costagliola D, Stingo V: (TTAGGG) telomeric sequence in selachian chromosomes. Heredity (Edinb) 87:583-588 (2001).

Rocco L, Morescalchi MA, Costagliola D, Stingo V: Karyotype and genome characterization in four cartilaginous fishes. Gene 295:289-298 (2002).

Rosa KO, Ziemniczak K, deBarros AV, Nogaroto V, Almeida MC, et al: Numeric and structural chromosome polymorphism in Rineloricaria lima (Silutiformes: Loricaridae): fusion points carrying $5 \mathrm{SrDNA}$ or telomere sequence vestiges. Rev Fish Biol Fisher 22:739-749 (2012).

Rossi AR, Gornung E, Sola L, Nirchio M: Comparative molecular cytogenetic analysis of two congeneric species, Mugil curema and M. liza (Pisces, Mugiliformes), characterized by significant karyotype diversity. Genetica 125 : 27-32 (2005).

Ruiz-Herrera A, Nergadze SG, Santagostino M, Giulotto E: Telomeric repeats far from the ends: mechanisms of origin and role in evolution. Cytogenet Genome Res 122:219-228 (2008).

Salvadori S, Deiana A, Coluccia E, Florida G, Rossi E, Zuffardi O: Colocalization of (TTAGGG) $)_{n}$ telomeric sequences and ribosomal genes in Atlantic eels. Chromosome Res 3:54-58 (1995). 
Scacchetti PC, Pansonato-Alves JC, Utsonomia R, Oliveira C, Foresti F: Karyotypic diversity in four species of the genus Gymnotus Linnaeus, 1758 (Teleostei, Gymnotiformes, Gymnotidae): physical mapping of ribosomal genes and telomeric sequences. Comp Cytogenet 5: 223-235 (2011).

Schmid M, Ziegler CG, Steinlein C, Nanda I, Schartl M: Cytogenetics of the bleak (Alburnus alburnus), with special emphasis on the $B$ chromosomes. Chromosome Res 14:231-242 (2006).

-Silva DS, Milhomem SSR, Pieczarka JC, Nagamachi CY: Cytogenetic studies in Eigenmannia virescens (Sternopygidae, Gymnotiformes) and new inferences on the origin of sex chromosomes in the Eigenmannia genus. BMC Genet 10:74 (2009).

-Slijepcevic P: Telomeres and mechanisms of Robertsonian fusions. Chromosoma 107:136-140 (1998).
Sola L, De Innocentiis S, Gornung E, Papalia S, Rossi AR, et al: Cytogenetic analysis of the Epinephelus marginatus (Pisces: Serranidae), with the chromosomal localization of the $18 \mathrm{~S}$ and $5 \mathrm{~S}$ rRNA genes and of the (TTAGGG) telomeric sequences. Mar Biol 137:45-51 (2000).

Sola L, Gornung E, Naoi H, Gunji R, Sato C, et al: FISH-mapping of $18 \mathrm{~S}$ ribosomal RNA genes and telomeric sequences in the Japanese bitterlings Rhodeus ocellatus kurumeus and Tanakia limbata (Pisces, Cyprinidae) reveals significant cytogenetic differences in morphologically similar karyotypes. Genetica 119:99-106 (2003a).

Sola L, Rossi AR, Annesi F, Gornung E: Cytogenetic studies in Sparus auratus (Pisces, Perciformes): molecular organization of $5 \mathrm{~S}$ rDNA and chromosomal mapping of $5 \mathrm{~S}$ and $45 \mathrm{~S} \mathrm{ri-}$ bosomal genes and telomeric repeats. Hereditas 139:232-236 (2003b)

-Srikulnath K, Uno Y, Matsubara K, Thongpan A, Suputtitada S, et al: Chromosomal localization of the 18S-28S and 5S rRNA genes and (TTAGGG) $)_{\mathrm{n}}$ sequences of butterfly lizards (Leiolepis belliana belliana and Leiolepis boehmei, Agamidae, Squamata). Genet Mol Biol 34:582-586 (2011)
Wang S, Su Y, Ding S, Cai Y, Wang J: Cytogenetic analysis of Orange spotted grouper, Epinephelus coioides, using chromosome banding and fluorescence in situ hybridization. Hydrobiologia 638:1-10 (2010).

Wiley JE, Meyne J, Little ML, Stout JC: Interstitial hybridization sites of the (TTAGGG) $)_{n}$ telomeric sequence on the chromosomes of some North American hylid frogs. Cytogenet Cell Genet 61:55-57 (1992).

Zhdanova NS, Minina JM, Karamisheva TV, Draskovic I, Rubtsov NB, Londoño-Vallejo $\mathrm{J}$-A: The very long telomeres in Sorex granaries (Soricidae, Eulipothyphla) contain ribosomal RNA. Chromosome Res 15:881-890 (2007).

Zijlmans JM, Martens UM, Poon SS, Raap AK, Tanke HJ, et al: Telomeres in the mouse have large inter-chromosomal variations in the number of $\mathrm{T}_{2} \mathrm{AG}_{3}$ repeats. Proc Natl Acad Sci USA 94:7423-7428 (1997). 